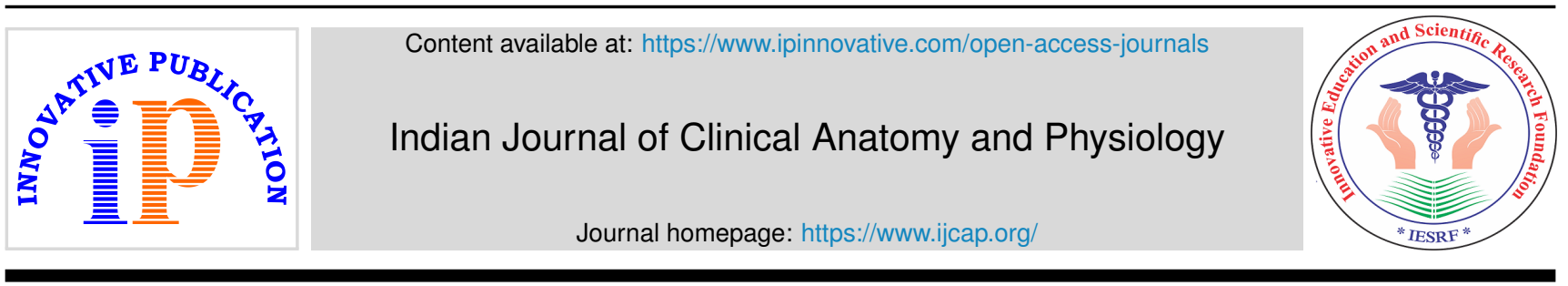

Original Research Article

\title{
Study of variations in the posterior part of the circle of Willis using magnetic resonance angiography
}

\author{
Merlin Leena Rajan ${ }^{1}$ ** \\ ${ }^{1}$ Dept. of Anatomy, Mount Zion Medical College Hospital, Pathanamthitta, Kerala, India
}

\section{A R T I C L E I N F O}

\section{Article history:}

Received 26-12-2020

Accepted 10-01-2021

Available online 12-04-2021

\section{Keywords:}

Circle of Willis

Magnetic resonance angiograms Variations

\begin{abstract}
A B S T R A C T
Background: The Circle of Willis is an arterial anastomosis uniting the internal carotid artery with the vertebro-basilar system. This cerebral arterial circle has ten components namely- the two anterior cerebral arteries, branches of internal carotid arteries, connected by the anterior communicating artery anteriorly, and the two posterior cerebral arteries, branches of basilar artery, connected to the internal carotid arteries via the two posterior communicating arteries.

Aims: The aim of this study was to study the variations in the formation of the posterior part of the circle of Willis using Magnetic Resonance Angiography (MRA), and to review the embryological and clinical perspectives.

Materials and Methods: The study was conducted over 18 months in the Department of Anatomy in collaboration with the Department of Radio-diagnosis at Pushpagiri Institute of Medical Sciences and Research Centre, Tiruvalla. MRA study was performed on 215 images, which were obtained from the electronic database at the Department of Radio-diagnosis. All the circles were further subdivided into complete and incomplete, both as a whole, and pertaining to the posterior parts, and analyzed.

Results: In this study, it was observed that the entire circle was complete in approximately $62-66 \%$ of the total, the posterior part being complete in approximately $66-76 \%$ of the total.

Conclusion: The incidences of variations were observed to be higher on the right side than on the left. The most frequent variation was the partial foetal variant of posterior cerebral artery (PCA) in the posterior part of the circle of Willis.

(C) This is an open access article distributed under the terms of the Creative Commons Attribution License (https://creativecommons.org/licenses/by/4.0/) which permits unrestricted use, distribution, and reproduction in any medium, provided the original author and source are credited.
\end{abstract}

\section{Introduction}

Circulus arteriosus/circle of Willis $^{1}$ is an arterial anastomosis at the base of the brain that unites internal carotid [ICA] and vertebro-basilar systems. Anteriorly, anterior cerebral arteries $[\mathrm{ACA}]$ are connected by Anterior communicating artery $[\mathrm{ACOA}]$ and posteriorly, the posterior cerebral artery [PCA] of each side (from basilar) is joined to ipsilateral ICA by posterior communicating artery [PCoA].

In the posterior part of circle of Willis, basilar artery runs cephalad in pre-pontine cistern and terminates at the level of inter-peduncular cistern by bifurcating behind dorsum sellae into two posterior cerebral arteries [PCA]. PCA pass

\footnotetext{
* Corresponding author.

E-mail address: merlinz.rajan@gmail.com (M. L. Rajan).
}

postero-laterally in circum-mesencephalic cistern, winds around cerebral peduncle and reaches above the tentorial surface, parallel with superior cerebellar artery and receives Posterior communicating artery $[\mathrm{PCoA}]$, a branch of $\mathrm{C}_{7}$ (communicating) segment of ICA.

Surgical nomenclature ${ }^{2-4}$ divides PCA into three parts (Figure 1)

1. $P_{1}$ segment from basilar bifurcation to junction with PCoA.

2. $\mathrm{P}_{2}$ segment from this junction to the portion in perimesencephalic cistern.

3. $\mathrm{P}_{3}$ segment that runs in calcarine fissure.

Clinically, this arterial ring has claimed widespread interest due to its propensity for variations relevant 
for neurosurgical, vascular and radiological interventional procedures especially with regard to cerebrovascular accidents.

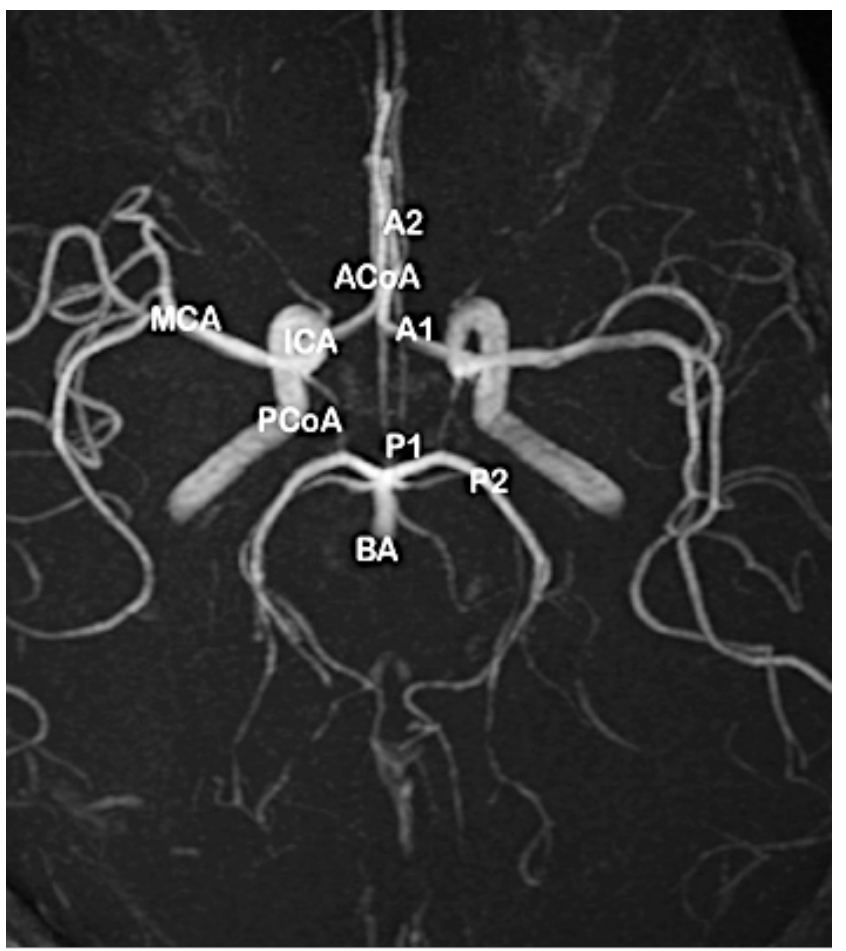

Fig. 1: Normal MRA image of Circle of Willis

\section{Materials and Methods}

The study design is an observational descriptive study conducted by the department of Anatomy in collaboration with department of Imaging \& Radio-Diagnosis at Pushpagiri Institute of Medical Sciences \& Research Centre, Tiruvalla. The investigative modality for the study was magnetic resonance angiography (MRA) of the brain. Cerebral imaging was performed on a $1.5 \mathrm{~T}$ MRI machine including axial T1, T2, and FLAIR (fluid attenuation inversion recovery) weighted sequences. Circle of Willis MRA was performed using three-dimensional (3D) timeoff flight (TOF) sequence. The original MRA sequence for each patient is retrieved from an electronic database $\left(\mathrm{DXMM} \mathrm{M}^{R}\right)$. The 215 subjects for the MRA study were taken up from those availing this investigation as part of their clinical workup or follow-up at the institute, on in-patient or outpatient basis. All MRAs of brain conducted in the institution on adults of both sexes in the age group between 18 and 90 years were included in the study. Those excluded were images with evidence of Neurosurgical interventions (AVM repair, shunting), known or diagnosed cases of vasculopathies such as arteritis, and known craniofacial anomalies and genetic disorders.

\section{Results}

Of the 215 images of the circle of Willis, 80 (37.21\%) were incomplete whereas $135(62.79 \%)$ were morphologically complete. In the posterior circulation, only 142 images had functional completeness, of which 86 showed textbook configuration (40\% of total, and $60.56 \%$ of the complete posterior circles).

\subsection{Morphology of component vessels}

According to the vessel size on MRA images, component vessels were grouped as normal, hypoplastic [partial foetal variant], hyperplastic, or absent [complete foetal variant]

\subsection{Posterior communicating artery}

PCoA was normal in $165(76.74 \%)$ images, on both right and left sides. The commonest variant observed was hyperplasia of right PCoA in 40 cases (18.6\%) and left PCoA in 34 cases (15.81\%). Hypoplasia was less frequent with four arteries affected on right and six on left side (Table 1). Total absence of PCoA and tortuosity of PCoA were also noted in ten images each respectively.

\subsection{P1 segment of posterior cerebral artery}

Of the 215 MRA images, right P1 segment was normal in 168 images $(78.14 \%)$, and the left P1 was normal in 177 cases $(82.33 \%)$. The commonest variation seen in P1 segment is the hypoplastic type or partial foetal variant, which occurred in 43 cases $(20 \%)$ on right side, and 37 cases $(17.21 \%)$ on left side. Total absence $(1.86 \%)$ of P1 segment was more frequent on right side (Table 2).

\subsection{Basilar artery}

The artery was noted to be essentially normal in all the studied images.

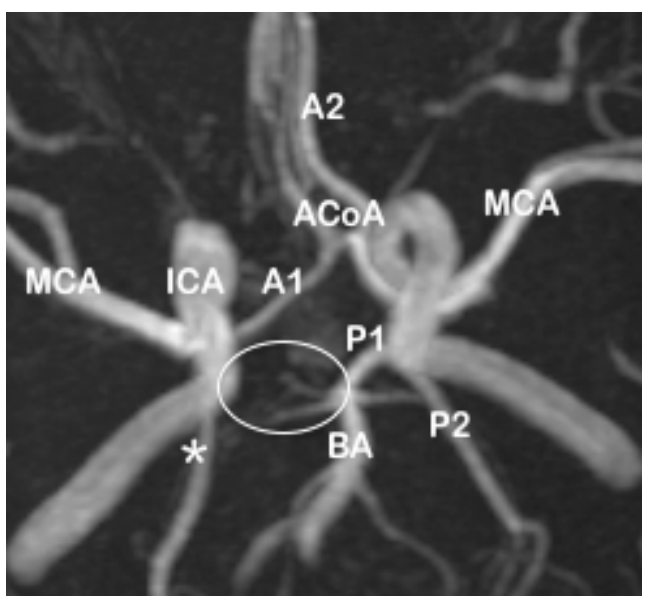

Fig. 2: Right p1 segment - complete foetal variant 
Table 1: Variations observed in Posterior Communicating arteries

\begin{tabular}{lcccc}
\hline Type of variation & Rt. PCoA & Lt. PCoA & Total & Incidence \\
Absent & $4(1.86 \%)$ & $6(2.79 \%)$ & 10 & $2.32 \%$ \\
Hyperplasia & $40(18.6 \%)$ & $34(15.81 \%)$ & 74 & $17.21 \%$ \\
Hypoplasia & $1(0.47 \%)$ & $5(2.3 \%)$ & 6 & $1.39 \%$ \\
Normal & $165(76.74 \%)$ & $165(76.74 \%)$ & 330 & $76.74 \%$ \\
Tortuous & $5(2.3 \%)$ & $5(2.3 \%)$ & 10 & $2.32 \%$ \\
Total & $215(100 \%)$ & $215(100 \%)$ & 430 & $100 \%$ \\
\hline
\end{tabular}

Table 2: Variations observed in P1 segment of Posterior cerebral artery

\begin{tabular}{lcccc}
\hline Type of variation & Right P1 & Left P1 & Total & Incidence \\
Absent, Foetal variant & $4(1.86 \%)$ & $1(0.47 \%)$ & 5 & $1.16 \%$ \\
Hypoplasia, partial foetal & $43(20 \%)$ & $37(17.21 \%)$ & 80 & $18.62 \%$ \\
variant & & $177(82.32 \%)$ & 345 & $80.23 \%$ \\
Normal & $168(78.14 \%)$ & $215(100 \%)$ & 430 & $100 \%$ \\
Total & $215(100 \%)$ & & \\
\hline
\end{tabular}

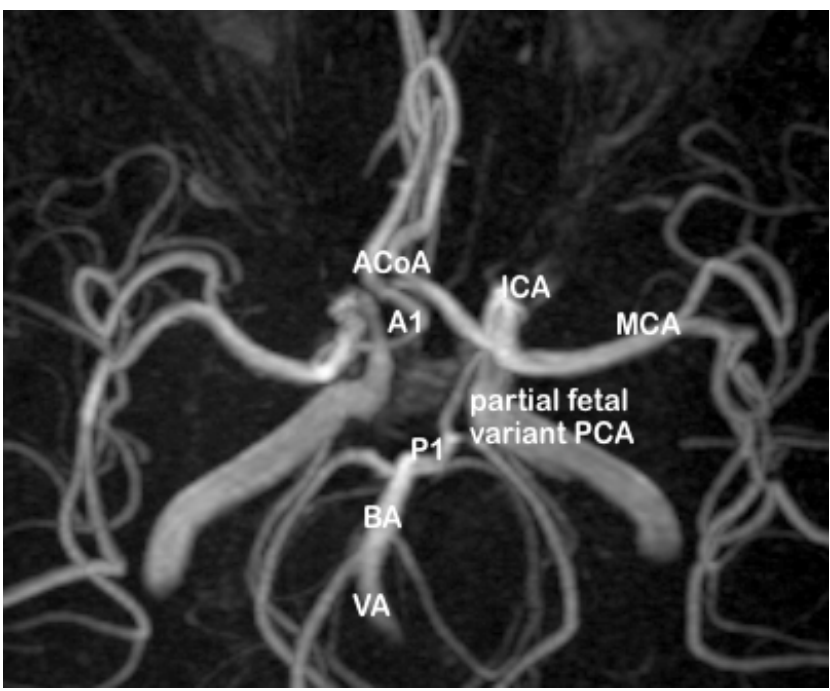

Fig. 3: Left p1 segment - partial foetal variant

\section{Discussion}

In the present study of the posterior part of the circle of Willis using MRA in 215 subjects, only 142 were functionally complete. The variation in the posterior part of the circle of Willis with the highest incidence was the partial foetal variant of $\mathrm{P} 1$ segment of PCA, with a higher incidence on the right side (19.07\%) as compared to the left (16.74\%).

Unilateral hypoplasia of PCoA was found to be similar in incidence (more on right than left) in a cadaveric study by Raghavendra et al. ${ }^{5}$ and Saha et al. ${ }^{6}$ Hypoplasia of right PCoA was observed in $0.47 \%$ MRAs, and left PCoA in $2.3 \%$ MRAs. Right P1 hypoplasia occurred in $0.93 \%$ and left P1 hypoplasia occurred in $0.47 \%$ MRAs.

Hypoplasia of right and left P1 segments (partial foetal variant) was seen to be associated with hyperplasia of corresponding PCoA [extremely significant statistically,

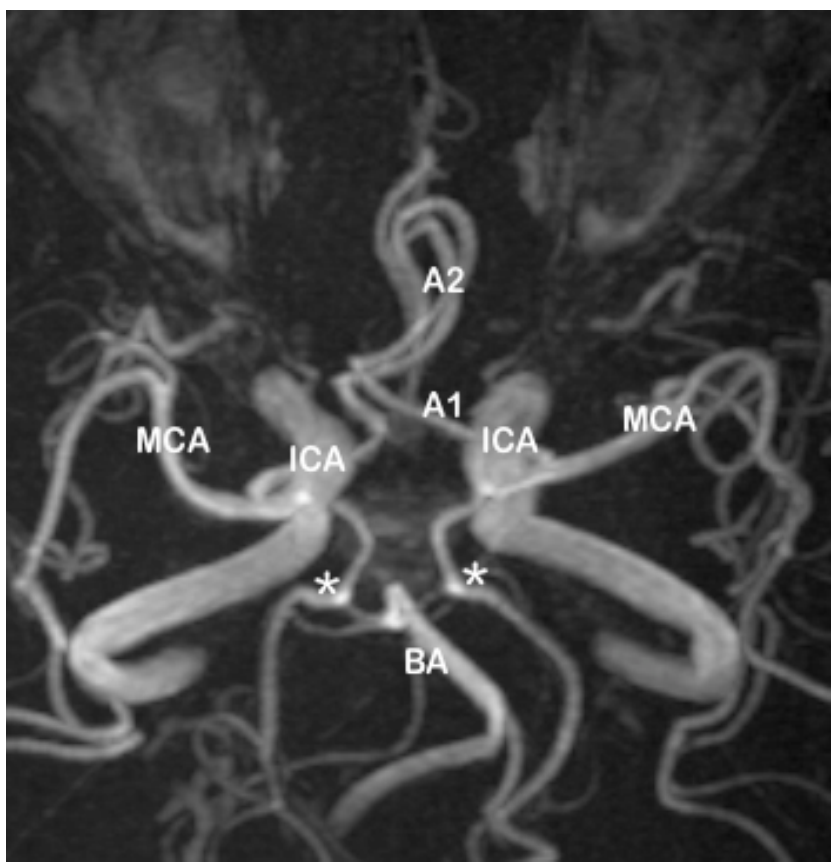

Fig. 4: P1 segment - Bilateral partial foetal variant

$\mathrm{p}<0.0001]$

Developmentally, ${ }^{7-9}$ in the posterior part, foetal origin of PCA occurs when the embryonic posterior cerebral artery (derived from ICA) fails to regress on the right or left sides or bilaterally. Most cases of P1 segment hypoplasia is due to the abnormal regression of the anastomosis between the primitive basilar artery and primitive PCA.

Clinically, the presence of variations in the posterior part can compromise vascular blood flow before or after transition from ICA to vertebro-basilar system can impair normal development of cerebellar hemispheres (as seen in PHACE syndrome). Moreover, variations in the posterior circulation are associated with a higher incidence of 


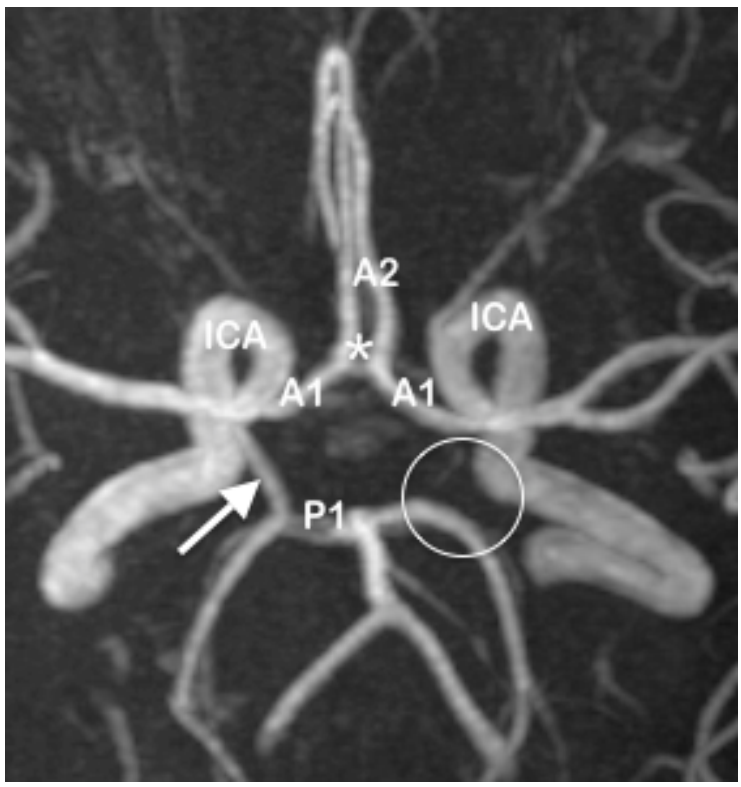

Fig. 5: Right P1 segment - Partial foetal variant, Left PCom absent

migraine and posterior cerebral infarcts with an associated increased stroke risk in patients with obstructive arterial disease. ${ }^{10}$ Hypoplasia or absence of PCoA is a risk factor for the occurrence of ipsilateral watershed infarction.

\section{Source of Funding}

None.

\section{Conflict of Interest}

The authors declare that there is no conflict of interest.

\section{References}

1. Standring S. Neuroanatomy: Vascular supply and drainage of the brain. In: Crossman A, editor. Gray's anatomy. Elsevier Churchill Livingstone; 2008. p. 247-54.

2. Morris P. Practical Neuroangiography. In: Part 2 Anatomy. Williams and Wilkins; 1997. p. 87-226.

3. Osborn AG. Osborn's Brain- Imaging, Pathology and Anatomy. 1st ed. Amirsys Publishing; 2013.

4. Butler P, Mitchell AWM, Healy JC, Healy. Central Nervous System: The Skull and Brain. In: Hogarth K, Jarosz J, Butler P, editors. Applied Radiological Anatomy. Cambridge University Press; 2012. p. 20-2.

5. Raghavendra, Shirol VS, Dixit D, Reddy AK, Desai SP. Circle of Willis and its variations; Morphometric study in adult human cadavers. Int J Med Res Health Sci. 2014;3(2):394-400. do1:10.5958/].23195886.3 .2087

6. Saha A, Bhagyalakshmi B, Mandal S, Banopadhyaya M. Variation of posterior communicating artery in human brain: A morphological study. Gomal Journal of Medical Sciences. 2013;11(1):42-46.

7. Kramer SP. On the function of the circle of Willis. J Exp Med. 1912;15(4):348-64. do1:10.1084/jem.15.4.348.

8. Padget DH. The circle of Willis. Its embryology and anatomy. In: Dandy WE, editor. In intracranial arterial aneurysms. New York: Comstock Publishing Company; 1948. p. 67-90.

9. Moffat DB. The development of posterior cerebral artery. Journal Anat Physiol;95(4)

10. Saikia B, Handique A, Phukan P, Lynser D, Sarma A. Circle of Willis: variant forms and their embryology using gross dissection and Magnetic Resonance Angiography. Int J Anat Res. 2014;2(2):344-53.

\section{Author biography}

Merlin Leena Rajan, Assistant Professor

Cite this article: Rajan ML. Study of variations in the posterior part of the circle of Willis using magnetic resonance angiography. Indian J Clin Anat Physiol 2021;8(1):11-14. 